Virginia Commonwealth University VCU Scholars Compass

2017

\title{
Rational design of super-alkalis and their role in $\mathrm{CO} 2$ activation
}

Tianshan Zhao

Peking University, Virginia Commonwealth University

Qian Wang

Peking University

Puru Jena

Virginia Commonwealth University, pjena@vcu.edu

Follow this and additional works at: http://scholarscompass.vcu.edu/phys_pubs

Part of the Physics Commons

This journal is (C) The Royal Society of Chemistry 2017

\section{Downloaded from}

http://scholarscompass.vcu.edu/phys_pubs/206

This Article is brought to you for free and open access by the Dept. of Physics at VCU Scholars Compass. It has been accepted for inclusion in Physics Publications by an authorized administrator of VCU Scholars Compass. For more information, please contact libcompass@vcu.edu. 


\section{Nanoscale}

rsc.li/nanoscale

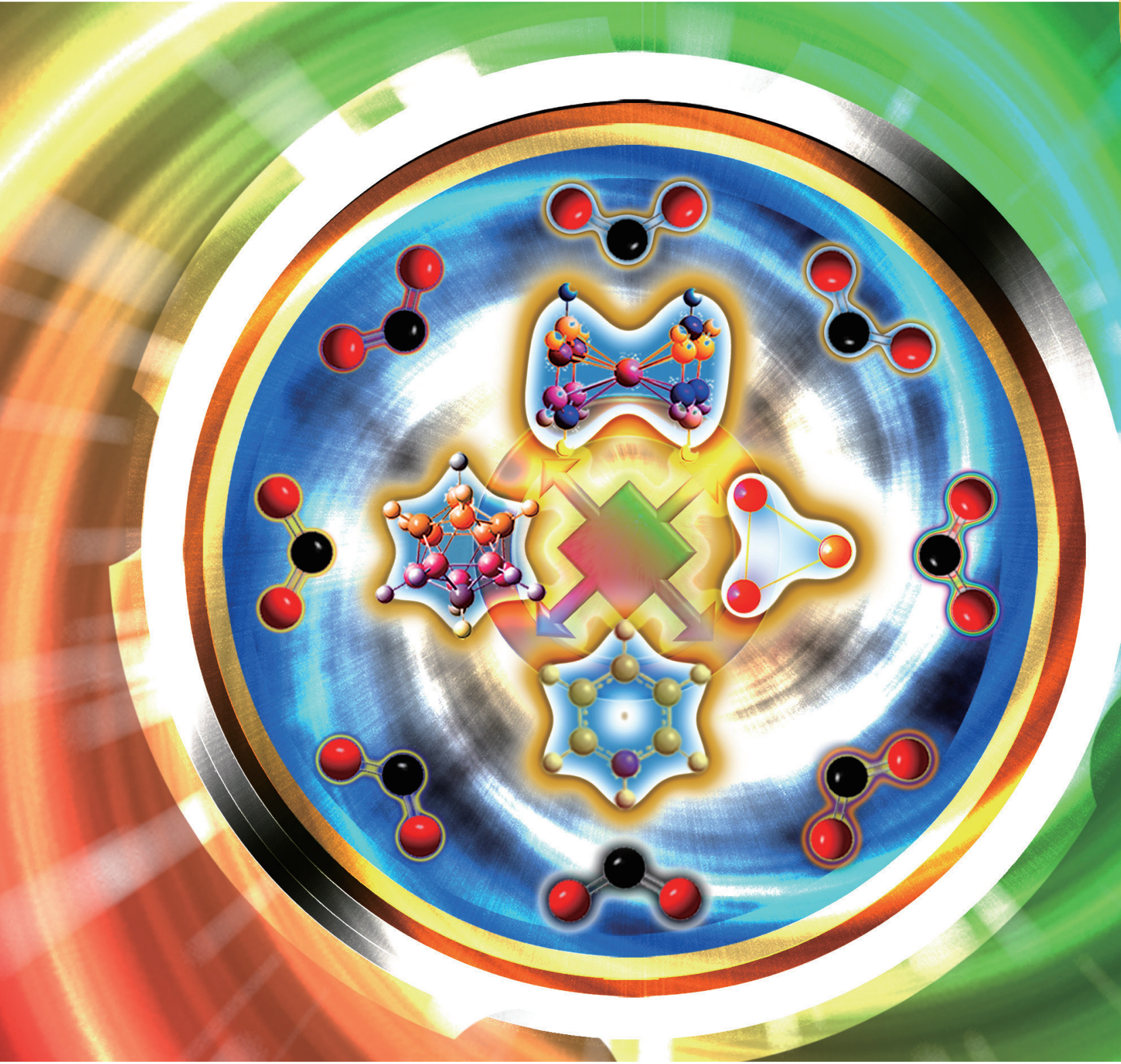

ISSN 2040-3372

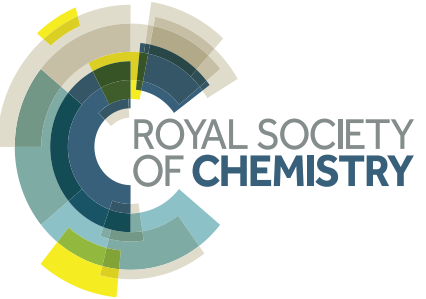




\title{
Nanoscale
}

PAPER
View Article Online

View Journal | View Issue

\section{A) Check for updates}

Cite this: Nanoscale, 2017, 9, 4891

\section{Rational design of super-alkalis and their role in $\mathrm{CO}_{2}$ activation $\uparrow$}

\begin{abstract}
Tianshan Zhao, ${ }^{a, b}$ Qian Wang*a and Puru Jena* ${ }^{* b}$
Super-alkalis are clusters of atoms. With ionization potentials smaller than those of the alkali atoms, they are playing an increasing role in chemistry as highlighted by recent applications in solar cells as well as in $\mathrm{Li}$-ion batteries. For the past 40 years superalkalis were designed using inorganic elements with the sp orbital character. Here, we show that a large class of superalkalis composed of only simple metal atoms, transition metal complexes as well as organic molecules can be designed by making use of electron counting rules beyond the octet rule. Examples include $\mathrm{Al}_{3}{ }^{+}, \mathrm{Mn}\left(\mathrm{B}_{3} \mathrm{~N}_{3} \mathrm{H}_{6}\right)_{2}{ }^{+}, \mathrm{B}_{9} \mathrm{C}_{3} \mathrm{H}_{12}{ }^{+}$, and $\mathrm{C}_{5} \mathrm{NH}_{6}{ }^{+}$which obey the jellium shell closure rule, the 18-electron rule, the Wade-Mingos rule, and Hückel's aromatic rule, respectively. We further show that the ability of superalkalis to transfer an electron easily can be used to activate $\mathrm{a} \mathrm{CO}_{2}$ molecule by transforming it from a linear to a bent structure. These results, based on density functional theory with generalized gradient approximation for exchange-correlation potential, open the door to a new class of catalysts for $\mathrm{CO}_{2}$ activation.
\end{abstract}

Received 10th January 2017

Accepted 8th February 2017

DOI: $10.1039 / \mathrm{c} 7 \mathrm{nr} 00227 \mathrm{k}$

rsc.li/nanoscale
Most of the early efforts in superhalogens were confined to simple metals (such as alkalis, $\mathrm{Mg}$, and $\mathrm{Al}$ ) decorated with halogens. The list of superhalogens has expanded greatly in the last decade as it was shown that they can be designed by using other electron counting rules such as the 18-electron rule ${ }^{5}$ Wade-Mingos rule, ${ }^{6}$ and aromatic rule. ${ }^{7}$ Superhalogens composed of only transition metals, ${ }^{5}$ transition metals and oxygen, ${ }^{8}$ as well as compositions that do not include a single metal or halogen atom ${ }^{5}$ are now known. The role of superhalogens as the building block of electrolytes in metal-ion batteries, ${ }^{9,10}$ hybrid perovskite solar cells, ${ }^{10}$ light emitting diodes, ${ }^{11}$ as well as hydrogen storage materials ${ }^{12}$ has further heightened their relevance in materials design. ${ }^{13}$

While nonmetallic as well as poly-nuclear superalkali cations with various functional groups as the central core have been studied, ${ }^{14}$ no attempts have been made, ${ }^{14,15}$ similar to those of superhalogens, to synthesize superalkalis using different electron counting rules. In this paper, we use the jellium rule, the 18-electron rule, the Wade-Mingos rule, and Hückel's aromatic rule to design superalkalis and examine their role in the activation of a $\mathrm{CO}_{2}$ molecule. The results are compared with the activation of $\mathrm{CO}_{2}$ using coinage metal atoms.

\section{Results and discussion}

\section{Rational design of super-alkalis}

Typical examples of superalkalis that have been studied earlier are $\mathrm{Li}_{3} \mathrm{O}, \mathrm{Cs}_{2} \mathrm{Cl}$, and $\mathrm{Cs}_{2} \mathrm{NO}_{3} \cdot{ }^{16,17}$ These moieties, analogous to 
those of alkali atoms, contain one extra electron than needed for the octet shell closure. The ionization potentials of these clusters, namely, $3.85 \mathrm{eV}, 3.00 \mathrm{eV}$, and $3.12 \mathrm{eV}$ (ref. 16) are smaller than those of alkali atoms $(5.39,5.14,4.34,4.18$, and $3.89 \mathrm{eV}$ for $\mathrm{Li}, \mathrm{Na}, \mathrm{K}, \mathrm{Rb}$, and $\mathrm{Cs}$, respectively). In the following we discuss how other electron counting rules that have been used to describe the stability of superhalogens can also be used to design superalkalis.

Jellium rule. The jellium model was introduced by Knight and coworkers to explain the pronounced stability of $\mathrm{Na}_{n}$ clusters containing $2,8,20,40, \ldots$ atoms. In this model a cluster is replaced by a sphere of uniform distribution of positive charge and the corresponding electronic energy levels and total energy are calculated. Because of the spherical symmetry of the potential, the electronic energy levels are arranged in $1 \mathrm{~s}^{2} 1 \mathrm{p}^{6} 1 \mathrm{~d}^{10} 2 \mathrm{~s}^{2} 1 \mathrm{f}^{14} \ldots$ shells. As each successive shell is filled, the corresponding cluster exhibits enhanced stability. Thus, $\mathrm{Na}_{n}$ clusters containing $2,8,20,40, \ldots$ atoms are more stable than their neighbors. A cluster containing 39 electrons would then need an extra electron for jellium shell closure just like a halogen atom with 7 electrons would require one extra electron to complete the $\mathrm{s}^{2} \mathrm{p}^{6}$ octet shell closure. Thus, $\mathrm{Al}_{13}$ would behave like a halogen atom. The measured electron affinity of $3.6 \mathrm{eV}$ of $\mathrm{Al}_{13}$ indeed confirmed ${ }^{18}$ this expectation.

By the same token, consider the $\mathrm{Al}_{3}$ cluster. Earlier studies have shown that $\mathrm{Al}$ in small clusters containing 7 or fewer number of atoms behaves as a monovalent species, ${ }^{18,19} \mathrm{Al}_{3}$ would then have 3 valence electrons, one more than that needed for the electron shell closure, just as is the case with alkali atoms. Thus, one would expect $\mathrm{Al}_{3}$ to behave as an alkali atom and if its ionization potential is less than that of an alkali atom, it could be termed a super-alkali. The situation would still be the same even if $\mathrm{Al}$ is considered to be trivalent in small clusters. $\mathrm{Al}_{3}$ would then contain 9 electrons, one more than needed for jellium shell closure. The computed geometry of $\mathrm{Al}_{3}{ }^{+}$is a planar triangle with a $C_{3 \mathrm{v}}$ symmetry and $\mathrm{Al}-\mathrm{Al}$ bond length of $2.68 \AA$ (see Fig. 1). This compares well with the previous result of $2.83 \AA$ (ref. 19) computed at the MP2 level of theory. The ionization potential calculated by taking the energy difference between the ground state of the neutral and the cation at the neutral geometry is $4.75 \mathrm{eV}$ (see Table 1). This is less than the ionization potential of the $\mathrm{Na}$ atom and confirms that superalkalis can be constructed from free-electron metals by using the jellium shell closure rule. To study the thermal stability of the $\mathrm{Al}_{3}{ }^{+}$super-alkali at finite temperature, we performed $a b$ initio molecular dynamics (AIMD) simulations at $400 \mathrm{~K}$. The time step was set as 1 femtosecond (fs). After 10 picoseconds of simulation, no structural distortion or reconstruction was found, and the average total potential energy remained nearly constant as shown in Fig. S1a, $\uparrow$ confirming that $\mathrm{Al}_{3}{ }^{+}$is thermally stable at room temperature. With regard to the simulated infrared (IR) spectroscopy, we found that the vibrational frequencies of $\mathrm{Al}_{3}{ }^{+}$are mainly distributed in the 200 to $250 \mathrm{~cm}^{-1}$ region; in the Raman spectroscopy, the peak distribution is around $270 \mathrm{~cm}^{-1}$. These results are given in Fig. S2a. $\dagger$

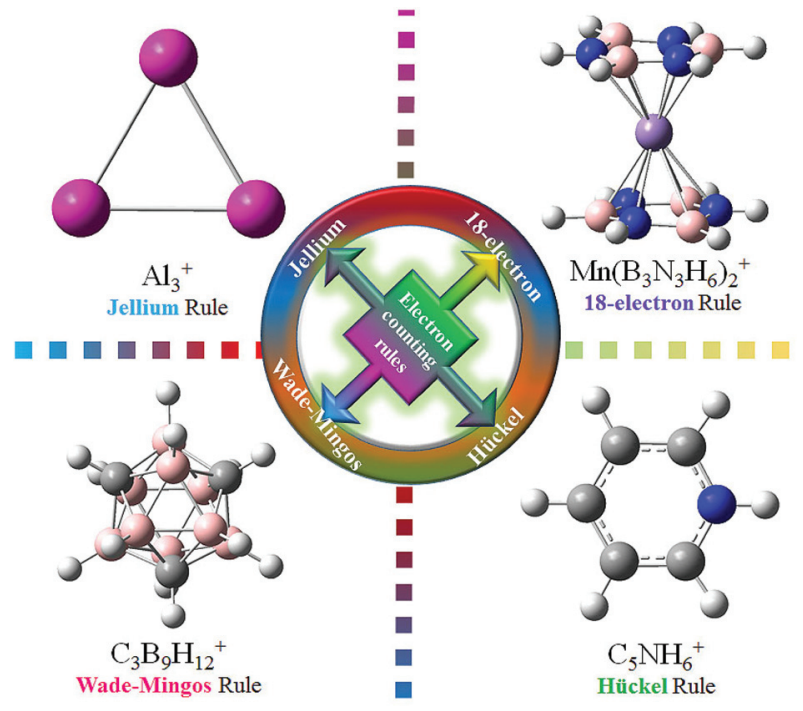

Fig. 1 Optimized geometries of four different kinds of superalkalis. Legends are cation's name and electron counting rules applied.

Table 1 Molecular volume, ionization potential (IP), O-C-O bond angle, average $\mathrm{C}-\mathrm{O}$ bond length, NBO charges transferred to $\mathrm{CO}_{2}$, and the HOMO-LUMO gap of superalkali cations. Results are compared with $\mathrm{CO}_{2}$ interacting with $\mathrm{Cu}, \mathrm{Ag}$, and $\mathrm{Au}^{20}$

\begin{tabular}{lcllllr}
\hline Cations & $\begin{array}{l}\text { Volume } \\
\left(\mathrm{cm}^{3} \mathrm{~mol}^{-1}\right)\end{array}$ & $\begin{array}{l}\text { IP } \\
(\mathrm{eV})\end{array}$ & $\begin{array}{l}\text { Angle } \\
\left({ }^{\circ}\right)\end{array}$ & $\begin{array}{l}\mathrm{C}-\mathrm{O} \\
\text { bond }(\AA)\end{array}$ & $\begin{array}{l}\text { NBO } \\
\text { charge } \\
\text { transfer }(e)\end{array}$ & $\begin{array}{l}\text { Gap } \\
(\mathrm{eV})\end{array}$ \\
\hline $\mathrm{Al}_{3}$ & 72.79 & 4.75 & 126 & 1.40 & 1.26 & 4.97 \\
$\mathrm{~B}_{9} \mathrm{C}_{3} \mathrm{H}_{12}$ & 126.83 & 3.64 & 131 & 1.29 & 0.91 & 14.77 \\
$\mathrm{C}_{5} \mathrm{NH}_{6}$ & 64.41 & 3.95 & 129 & 1.35 & 0.63 & 11.65 \\
$\mathrm{Mn}\left(\mathrm{B}_{3} \mathrm{~N}_{3} \mathrm{H}_{6}\right)_{2}$ & 127.10 & 4.35 & 133 & 1.25 & 0.90 & 6.79 \\
$\mathrm{CO}_{2}^{-}($anion) & & & 137 & 1.24 & 1 & \\
$\mathrm{Cu}$ & - & 7.73 & 139 & 1.22 & 0.64 & - \\
$\mathrm{Ag}$ & - & 7.58 & 173.5 & 1.16 & - & - \\
$\mathrm{Au}$ & - & 9.23 & 145 & 1.20 & 0.45 & -
\end{tabular}

From an analysis of the frontier molecular orbitals (FMOs) of a neutral $\mathrm{Al}_{3}$ cluster shown in Fig. S3a† we find that the highest occupied molecular orbital (HOMO) is mainly contributed by aluminum $3 \mathrm{p}_{z}$ orbitals. The lowest unoccupied molecular orbital (LUMO) mainly exhibits $\sigma$ bonding. The HOMOLUMO gap is estimated to be $4.97 \mathrm{eV}$, which also confirms the unusual stability of the cation in the gas phase. To be specific, the electron configuration of each $\mathrm{Al}$ atom in $\mathrm{Al}_{3}{ }^{+}$is $3 \mathrm{~s}^{1.68} 3 \mathrm{p}^{0.97}$, which means that aluminum loses $0.32 \mathrm{~s}$ orbital electrons per atom. This is a simple example of how the jellium shell closure rule can be used to design superalkalis. In the later part of the section we will discuss the role $\mathrm{Al}_{3}{ }^{+}$can play in $\mathrm{CO}_{2}$ activation.

We also considered a hetero-atomic cluster $\mathrm{Al}_{12} \mathrm{~N}$ which has $12 \times 3+5=41$ electrons, one electron more than needed for the jellium shell closure. The calculated ionization potential of $\mathrm{Al}_{12} \mathrm{~N}$ is $4.81 \mathrm{eV}$ which confirms that it too is a superalkali.

18-Electron rule. This rule generally applies to complexes containing transition metal atoms which require 18 electrons 
to fill the $\mathrm{s}^{2} \mathrm{p}^{6} \mathrm{~d}^{10}$ orbitals. Classic examples of a stable compound obeying the 18-electron rule are ferrocene, $\mathrm{Fe}\left(\mathrm{C}_{5} \mathrm{H}_{5}\right)_{2}$, where the Fe atom is sandwiched between two $\mathrm{C}_{5} \mathrm{H}_{5}$ molecules and chromium bis-benzene, $\operatorname{Cr}\left(\mathrm{C}_{6} \mathrm{H}_{6}\right)_{2}$, where the $\mathrm{Cr}$ atom is sandwiched between two benzene molecules. With the $3 \mathrm{~d}^{6} 4 \mathrm{~s}^{2}$ $\left(3 d^{5} 4 s^{1}\right)$ electronic configuration of the $\mathrm{Fe}(\mathrm{Cr})$ atom and $5(6)$ $\pi$-electrons coming from each of the $\mathrm{C}_{5} \mathrm{H}_{5}\left(\mathrm{C}_{6} \mathrm{H}_{6}\right)$ molecules, $\mathrm{Fe}\left(\mathrm{C}_{5} \mathrm{H}_{5}\right)_{2}$ and $\mathrm{Cr}\left(\mathrm{C}_{6} \mathrm{H}_{6}\right)_{2}$ contain 18-electrons each which account for their unusual stability. Similarly, it was predicted ${ }^{21}$ and later experimentally verified ${ }^{22}$ that $\mathrm{Au}_{12} \mathrm{~W}$ with 18 electrons is unusually stable and $\mathrm{Au}_{12} \mathrm{Ta}$, which contains one less electron than required by the 18-electron rule, has an electron affinity of $3.65 \mathrm{eV},{ }^{5}$ thus behaving as a superhalogen. We explored if the 18-electron rule can be successfully used to design a superalkali.

Here we show that the $\operatorname{Mn}\left(\mathrm{B}_{3} \mathrm{~N}_{3} \mathrm{H}_{6}\right)_{2}{ }^{+}$cation which is isoelectronic with $\mathrm{Cr}\left(\mathrm{C}_{6} \mathrm{H}_{6}\right)_{2}{ }^{23}$ is very stable and neutral $\mathrm{Mn}\left(\mathrm{B}_{3} \mathrm{~N}_{3} \mathrm{H}_{6}\right)_{2}$ which contains one electron more than needed to satisfy the 18-electron rule is a superalkali. We optimized the geometry of $\mathrm{Mn}\left(\mathrm{B}_{3} \mathrm{~N}_{3} \mathrm{H}_{6}\right)_{2}$ by starting with different configurations as given in the ESI. $\dagger$ The ground state geometry is that of the Mn atom sandwiched between two planar borazene rings with $\mathrm{B}$ facing $\mathrm{N}$ (see Fig. 1). The B-N, B-Mn, and N-Mn bond lengths are 1.45, 2.59, and $2.44 \AA$ in $\mathrm{Mn}\left(\mathrm{B}_{3} \mathrm{~N}_{3} \mathrm{H}_{6}\right)_{2}{ }^{+}$, with two borazene planes separated by $3.23 \AA$. The magnetic moment of $4 \mu_{\mathrm{B}}$ is localized at the $\mathrm{Mn}$ site. To examine the effect of on-site Coulomb repulsion on the magnetic moment we repeated our calculation with Hubbard $U$ ranging from 2 to $5 \mathrm{eV}$. The magnetic moment of $\mathrm{Mn}$ in the $\mathrm{Mn}\left(\mathrm{B}_{3} \mathrm{~N}_{3} \mathrm{H}_{6}\right)_{2}{ }^{+}$cation and $\mathrm{Mn}\left(\mathrm{B}_{3} \mathrm{~N}_{3} \mathrm{H}_{6}\right)_{2}$ neutral cluster remained at $4 \mu_{\mathrm{B}}$ and $3 \mu_{\mathrm{B}}$, respectively, independent of the value of $U$ adopted. More information is given in the ESI. $\dagger$

The HOMO-LUMO gap of $\mathrm{Mn}\left(\mathrm{B}_{3} \mathrm{~N}_{3} \mathrm{H}_{6}\right)_{2}{ }^{+}$is $6.79 \mathrm{eV}$ which is a consequence of the 18-electron shell closure rule and confirms the stability of the cation. The HOMO reflects a $\pi$ bonding character and is more delocalized on the B-N dimers. Details of electron configuration are given in ESI text $1 . \dagger$ The ionization potential of $\mathrm{Mn}\left(\mathrm{B}_{3} \mathrm{~N}_{3} \mathrm{H}_{6}\right)_{2}$, namely, $4.35 \mathrm{eV}$ (see Table 1), shows that it is a super-alkali. To examine the thermal stability of $\mathrm{Mn}\left(\mathrm{B}_{3} \mathrm{~N}_{3} \mathrm{H}_{6}\right)_{2}{ }^{+}$we carried out AIMD simulations at $800 \mathrm{~K}$ for $10 \mathrm{ps}$ with ten thousand steps. The fluctuation of the total potential energy during the simulation time is given in Fig. S1b. $\dagger$ The average value of the total potential energy remains nearly constant during the entire time scale, confirming that the $\mathrm{Mn}\left(\mathrm{B}_{3} \mathrm{~N}_{3} \mathrm{H}_{6}\right)_{2}{ }^{+}$super-alkali is stable at high temperature. By observing the simulated IR spectra, we found that the vibrational frequency distributions of $\mathrm{Mn}\left(\mathrm{B}_{3} \mathrm{~N}_{3} \mathrm{H}_{6}\right)_{2}{ }^{+}$are in the 430, 970, 1400, 2700, and $3600 \mathrm{~cm}^{-1}$ regions. There are only three main peaks in the 890,2700 , and $3600 \mathrm{~cm}^{-1}$ regions of Raman spectra as shown in Fig. S2b. $\dagger$

Wade-Mingos rule. The poly skeletal electron pairing theory (PSEPT) was developed by Wade ${ }^{24,25}$ and Mingos ${ }^{26,27}$ to account for the stability of boron-based electron deficient compounds such as boranes. The rule states that $(2 n+1)$ pairs of electrons are needed to stabilize closo-boranes $\left(\mathrm{B}_{n} \mathrm{H}_{n}{ }^{2-}\right)$ where $n$ is the number of vertices in the boron polyhedron. Consider, for example, $\mathrm{B}_{12} \mathrm{H}_{12}{ }^{2-}$. The geometry of this moiety is an icosahedron with 12 vertices occupied by $12 \mathrm{~B}$ atoms. The $12 \mathrm{H}$ atoms are radially bonded to these $\mathrm{B}$ atoms. With four electrons contributed by each $\mathrm{BH}$ pair, there are a total of 48 electrons in $\mathrm{B}_{12} \mathrm{H}_{12}$. Of these 24 electrons are occupied forming the $12 \mathrm{BH}$ covalent bonds, leaving behind 24 electrons to contribute to cage bonding. However, according to the WadeMingos rule $50-24=26$ electrons are needed for cage bonding. Thus, $\mathrm{B}_{12} \mathrm{H}_{12}$ is stable only as a dianion.

Pathak et $a{ }^{6}{ }^{6}$ used the Wade-Mingos rule to design a superhalogen. They accomplished this by replacing one of the $\mathrm{B}$ atoms in closo-borane with a $\mathrm{C}$ atom. Thus, $\mathrm{CB}_{n-1} \mathrm{H}_{n}$ would need only one electron to stabilize the molecule. The authors showed that the electron affinity of $\mathrm{CB}_{11} \mathrm{H}_{12}$ is $5.39 \mathrm{eV}{ }^{6}$ thus confirming that it is indeed a superhalogen.

We have explored the possibility that the Wade-Mingos rule can also be used to design a superalkali. Thus, we looked for a molecule that would have one electron more than needed to satisfy the Wade-Mingos rule. We considered $\mathrm{B}_{9} \mathrm{C}_{3} \mathrm{H}_{12}$ formed by replacing three $\mathrm{B}$ atoms in $\mathrm{B}_{12} \mathrm{H}_{12}$ with $\mathrm{C}$ atoms. The $\mathrm{B}_{9} \mathrm{C}_{3} \mathrm{H}_{12}$ moiety has a total of 51 electrons $(9 \times 3+3 \times 4+12 \times 1)$, one more than $(2 n+1)$ pairs of electrons needed for the Wade-Mingos shell closure rule. Thus, $\mathrm{B}_{9} \mathrm{C}_{3} \mathrm{H}_{12}{ }^{+}$should be a stable molecule. We optimized the geometry of $\mathrm{B}_{9} \mathrm{C}_{3} \mathrm{H}_{12}$ by examining different isomers (see Fig. S5 $\dagger$ ). The lowest energy structure is given in Fig. 1 where carbon atoms occupy $(1,7,9)$ sites in $\mathrm{B}_{9} \mathrm{C}_{3} \mathrm{H}_{12}{ }^{+}$. The stable $\mathrm{B}_{9} \mathrm{C}_{3} \mathrm{H}_{12}{ }^{+}$structure possesses a $C_{3 \mathrm{v}}$ symmetry with a closo-dodecaborate structure which is similar to the $\mathrm{B}_{12} \mathrm{H}_{12}{ }^{2-}$ structure ${ }^{28}$ shown in Fig. 1 . The $\mathrm{B}-\mathrm{B}$ and $\mathrm{B}-\mathrm{C}$ bond lengths are around 1.79 and $1.72 \AA$ in the $\mathrm{B}_{9} \mathrm{C}_{3} \mathrm{H}_{12}{ }^{+}$cation (quite close to the $1.78 \AA \mathrm{A}-\mathrm{B}$ bond length in the $\mathrm{B}_{12} \mathrm{H}_{12}{ }^{2-}$ structure ${ }^{28}$ ).

The calculated ionization potential of $\mathrm{B}_{9} \mathrm{C}_{3} \mathrm{H}$ is $3.64 \mathrm{eV}$ (Table 1) which confirms that it is a superalkali. The thermal stability of $\mathrm{B}_{9} \mathrm{C}_{3} \mathrm{H}_{12}{ }^{+}$is confirmed by AIMD, with the Nosé heat bath scheme at $800 \mathrm{~K}$ for $10 \mathrm{ps}$, as shown in Fig. S1c. $\dagger$ No distortion or reconstruction of the boron cage is found, and the average total potential energy remains nearly constant. We found that the simulated vibrational frequencies of $\mathrm{B}_{9} \mathrm{C}_{3} \mathrm{H}_{12}{ }^{+}$ are at $870,1100,1230,2700$, and $3200 \mathrm{~cm}^{-1}$ of IR modes and 870,2700 , and $3300 \mathrm{~cm}^{-1}$ regions of Raman modes, respectively, as shown in Fig. S2c. $\dagger$

By analyzing the FMOs in Fig. S3c $\dagger$ we see that the HOMO is more delocalized on the cage skeleton while the LUMO is localized on C and H, with a HOMO-LUMO gap of $14.77 \mathrm{eV}$. Details of electron configuration are given in ESI text $2 . \dagger$

Hückel's rule. The stability of aromatic molecules is governed by Hückel's rule which requires $(4 n+2)$ electrons for a molecule to be aromatic. A classic example of an aromatic molecule is benzene $\left(\mathrm{C}_{6} \mathrm{H}_{6}\right)$ which contains $6 \pi$ electrons. Here $n=1$. To see if an organic molecule mimicking an alkali atom can be designed using Hückel's rule, we consider pyridine- $\mathrm{H}^{+}$ $\left(\mathrm{C}_{5} \mathrm{NH}_{6}{ }^{+}\right)$(see Fig. 1) where a tetravalent $\mathrm{C}$ atom is replaced by a pentavalent $\mathrm{N}$ atom. Thus, $\mathrm{C}_{5} \mathrm{NH}_{6}$ contains $7 \pi$ electrons, one more than needed to satisfy Hückel's rule. The geometry of the stable $\mathrm{C}_{5} \mathrm{NH}_{6}{ }^{+}$cation has a planar hexagonal configuration 
with a $C_{2 \mathrm{v}}$ symmetry and all carbon and nitrogen atoms contribute one $\mathrm{p}$ electron each to the delocalized $\pi$ orbital. The $\mathrm{C}-\mathrm{C}$ and $\mathrm{C}-\mathrm{N}$ bond lengths of $\left(\mathrm{C}_{5} \mathrm{NH}_{6}^{+}\right)$are 1.41 and $1.37 \AA$, respectively. In order to confirm the stability and aromaticity of $\mathrm{C}_{5} \mathrm{NH}_{6}{ }^{+}$we calculated the nucleus-independent chemical shift (NICS) as well as the electron localization function (ELF). With NICS(0) and NICS(1) values at -7.78 and -9.34 , respectively, and a delocalized $\pi$ character we see that $\mathrm{C}_{5} \mathrm{NH}_{6}{ }^{+}$is aromatic. The details of our calculations are given in ESI texts 3 and $4 . \dagger$

The ionization potential of $\mathrm{C}_{5} \mathrm{NH}_{6}$ is $3.95 \mathrm{eV}$, confirming that it is a superalkali (see Table 1). To further confirm the thermodynamic stability of pyridine- $\mathrm{H}^{+}$, we followed the same method and criteria as for other systems. The temperature and potential energy plots corresponding to the initial and final snapshots are given in Fig. S1d, $\dagger$ which confirm its stability. The IR vibrational frequency distributions of pyridine $-\mathrm{H}^{+}$are located at 600,1600 , and $3500 \mathrm{~cm}^{-1}$, and Raman frequencies are located at 1000 and $3200 \mathrm{~cm}^{-1}$, as shown in Fig. S2d. $\dagger$

The HOMO-LUMO gap of $\mathrm{C}_{5} \mathrm{NH}_{6}{ }^{+}$is $11.65 \mathrm{eV}$ with the HOMO residing at the $\mathrm{C}-\mathrm{C} \pi$ bonding orbital and the LUMO is located at the $\mathrm{C}$ and $\mathrm{N} \mathrm{p}_{z}$ anti-bonding orbitals as shown in Fig. S3d. $\dagger$ Results of the electron configuration are given in ESI text $5 . \dagger$

\section{Role of superalkalis in $\mathrm{CO}_{2}$ activation}

Carbon dioxide, a major contributor to global warming, is a covalently bonded linear molecule in which carbon exists in its highest oxidation state. To convert $\mathrm{CO}_{2}$ into fuel, catalysts are needed to first activate $\mathrm{CO}_{2}$, i.e. it must transform from the linear to a bent structure. This can be accomplished by adding an electron as $\mathrm{CO}_{2}{ }^{-}$is known to have a bent geometry. ${ }^{29}$ However, with an electron affinity of $-0.6 \mathrm{eV} \mathrm{CO}_{2}{ }^{-}$is metastable. Thus, studies of $\mathrm{CO}_{2}$ activation have focused on anionic complexes involving $\mathrm{CO}_{2}$ and various atoms and molecules.

In a recent work, Bowen and coworkers ${ }^{20}$ carried out a combined photoelectron spectroscopy and computational study of $\left(\mathrm{M}-\mathrm{CO}_{2}\right)^{-}$anions $(\mathrm{M}=\mathrm{Cu}, \mathrm{Ag}, \mathrm{Au})$. They found that while $\left(\mathrm{Ag}-\mathrm{CO}_{2}\right)^{-}$and $\left(\mathrm{Cu}-\mathrm{CO}_{2}\right)^{-}$exist only in the physisorbed and chemisorbed states, respectively, $\left(\mathrm{Au}-\mathrm{CO}_{2}\right)^{-}$exists in both physisorbed and chemisorbed states. Since $\mathrm{CO}_{2}$ would assume a bent structure when an electron is transferred to it or due to its interaction with the electrons of the metal atom, ${ }^{29}$ one would expect that the stable geometry of $\left(\mathrm{M}-\mathrm{CO}_{2}\right)^{-}$would depend upon the ionization potential of the metal atom, M; an atom with a smaller ionization potential should be able to transfer an electron to $\mathrm{CO}_{2}$ more easily than one with a large ionization potential. Similarly, the Coulomb repulsion from the metal atom would also bend the linear $\mathrm{CO}_{2}$ structure. ${ }^{29}$

To see if this intuitive idea is borne out by actual calculation, we present in Fig. 2 the geometry of (a) $\mathrm{CO}_{2}$ and (b) $\mathrm{CO}_{2}{ }^{-}$. Neutral $\mathrm{CO}_{2}$ is a linear molecule with a $\mathrm{C}-\mathrm{O}$ bond of $1.20 \AA . \mathrm{CO}_{2}^{-}$, on the other hand, is a bent structure with an $\mathrm{O}-\mathrm{C}-\mathrm{O}$ bond angle of $137^{\circ}$ and a stretched $\mathrm{C}-\mathrm{O}$ bond of $1.24 \AA$. The electron configuration of $\mathrm{C}$ and $\mathrm{O}$ in $\mathrm{CO}_{2}$ is $2 \mathrm{~s}^{0.91} 2 \mathrm{p}^{1.99}$ and $2 \mathrm{~s}^{1.79} 2 \mathrm{p}^{4.73}$. Once an electron is transferred, $\mathrm{CO}_{2}{ }^{-}$develops
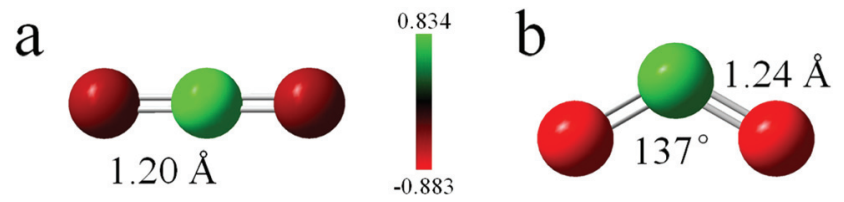

Fig. 2 Optimized geometries with bond angles and $\mathrm{CO}$ bond distances, and the NBO charge distribution in (a) neutral $\mathrm{CO}_{2}$ and (b) $\mathrm{CO}_{2}{ }^{-}$anion.

a magnetic moment of $1 \mu_{\mathrm{B}}$ and the $\alpha$-spin and $\beta$-spin of $\mathrm{C}$ electron configurations are $2 \mathrm{~s}^{0.61} 2 \mathrm{p}^{1.36}$ and $2 \mathrm{~s}^{0.88} 2 \mathrm{p}^{2.62}$ and $\mathrm{O}$ electron configurations are $2 \mathrm{~s}^{0.37} 2 \mathrm{p}^{0.90}$ and $2 \mathrm{~s}^{0.88} 2 \mathrm{p}^{2.48}$, respectively. The carbon atoms are sp hybridized in $\mathrm{CO}_{2}$ and become quasi-sp ${ }^{2}$ hybridized in $\mathrm{CO}_{2}^{-}$, resulting in a bent structure.

We note that the ionization potentials of $\mathrm{Cu}, \mathrm{Ag}$, and $\mathrm{Au}$, are, respectively, $7.73 \mathrm{eV}, 7.58 \mathrm{eV}$, and $9.23 \mathrm{eV}$. Bowen and coworkers found the calculated $\mathrm{O}-\mathrm{C}-\mathrm{O}$ angles of $\left(\mathrm{Cu}-\mathrm{CO}_{2}\right)^{-}$and $\left(\mathrm{Au}-\mathrm{CO}_{2}\right)^{-}$to be $139.7^{\circ}$ and $145.0^{\circ}$, respectively, while the geometry of $\mathrm{CO}_{2}$ in $\left(\mathrm{Ag}-\mathrm{CO}_{2}\right)^{-}$remained linear. However, one would have expected it to be a bent structure as in the case of $\left(\mathrm{Cu}-\mathrm{CO}_{2}\right)^{-}$because both $\mathrm{Cu}$ and $\mathrm{Ag}$ have nearly the same ionization potential. These counter-intuitive results suggest that both the electronic structure and the size of the metal atom play a role in electron transfer.

As seen above, the ionization potentials of superalkalis are less than those of alkali atoms and their rational design using different electron counting rules implies that they have different electronic structures. Thus, a systematic study of the interaction of these superalkalis with $\mathrm{CO}_{2}$ can shed light on the relative role ionization potential and the underlying electronic structure of species play on $\mathrm{CO}_{2}$ activation. In the following we discuss these results.

Jellium rule. We study the interaction of $\mathrm{Al}_{3}$ with $\mathrm{CO}_{2}$. In neutral $\mathrm{Al}_{3}$, its HOMO has a large density distribution around $\mathrm{Al}$ atoms in the triangle plane as in Fig. S4a, $\uparrow$ which would make $\mathrm{CO}_{2}$ prefer to adsorb at the position where the charge density is maximum. In the stable configuration as shown in Fig. 3a, the distance between $\mathrm{CO}_{2}{ }^{-}$and $\mathrm{Al}_{3}{ }^{+}$is $1.95 \AA$, the O-C

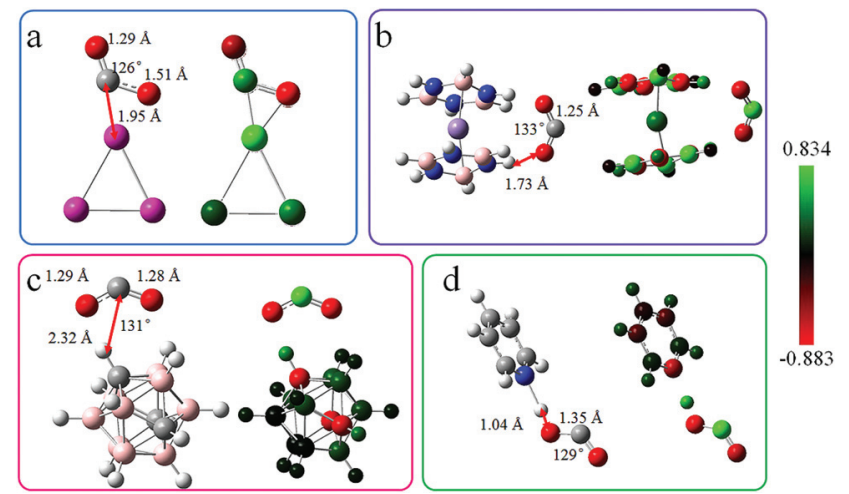

Fig. 3 (a) to (d) Optimized geometries (left panel) and NBO charge distribution (right panel) of four different kinds of neutral superalkalis interacting with the $\mathrm{CO}_{2}$ molecule. 
bonds extend to 1.29 and $1.51 \AA$, about $4.4 \%-22 \%$ longer than that in the $\mathrm{CO}_{2}$ anion. This bond stretching is the result of bond weakening, making it easier to activate the $\mathrm{CO}_{2}$ molecule. The corresponding $\mathrm{O}-\mathrm{C}-\mathrm{O}$ angle in $\mathrm{Al}_{3} \mathrm{CO}_{2}$ is $126^{\circ}$ making the bond-bending $8 \%$ larger than the corresponding value in $\mathrm{CO}_{2}{ }^{-}$. This is consistent with the amount of charge transfer. Natural bond orbital (NBO) analysis in Fig. 3a shows that $1.26 e$ charge is transferred from $\mathrm{Al}_{3}$ to $\mathrm{CO}_{2}$ (see Table 1) which is larger than that in a noble metal atom $(0.77 e),{ }^{30}$ and the $\mathrm{CO}_{2}$ anion $(1 e)$.

In neutral $\mathrm{Al}_{3}$ the $\alpha$-spin and $\beta$-spin electron configurations of $\mathrm{Al}$ are $3 \mathrm{~s}^{0.78} 3 \mathrm{p}^{0.87}$ and $3 \mathrm{~s}^{0.61} 3 \mathrm{p}^{0.72}$, respectively. When the $\mathrm{CO}_{2}$ is adsorbed, the $\alpha$-spin and $\beta$-spin electron configurations of $\mathrm{Al}$ change to $3 \mathrm{~s}^{0.78} 3 \mathrm{p}^{0.66}$ and $3 \mathrm{~s}^{0.79} 3 \mathrm{p}^{0.33}$ in $\mathrm{Al}_{3}$ and that of $\mathrm{C}$ and $\mathrm{O}$ are $2 \mathrm{~s}^{0.55} 2 \mathrm{p}^{1.22}$ and $2 \mathrm{~s}^{0.89} 2 \mathrm{p}^{2.53} ; 2 \mathrm{~s}^{0.54} 2 \mathrm{p}^{1.21}$ and $2 \mathrm{~s}^{0.89} 2 \mathrm{p}^{2.53}$ in $\mathrm{CO}_{2}$. The electron gain of $0.57 e$ in the $\alpha$-spin and $0.59 e$ in the $\beta$-spin configurations results in the bending of $\mathrm{CO}_{2}$.

18-Electron rule. Here we study the interaction between $\mathrm{Mn}\left(\mathrm{B}_{3} \mathrm{~N}_{3} \mathrm{H}_{6}\right)_{2}$ and $\mathrm{CO}_{2}$. The corresponding geometry is given in Fig. 3b. Note that the $\mathrm{O}$ atom of $\mathrm{CO}_{2}$ is bound to the $\mathrm{H}$ atom that is attached to $\mathrm{N}$. The distance between $\mathrm{CO}_{2}$ and $\mathrm{Mn}\left(\mathrm{B}_{3} \mathrm{~N}_{3} \mathrm{H}_{6}\right)_{2}$ is $1.73 \AA$. Both the $\mathrm{O}-\mathrm{C}$ bonds are extended to $1.25 \AA$ which is slightly longer than that of $1.24 \AA$ in $\mathrm{CO}_{2}{ }^{-}$. The $\mathrm{O}-\mathrm{C}-\mathrm{O}$ angle in $\mathrm{Mn}\left(\mathrm{B}_{3} \mathrm{~N}_{3} \mathrm{H}_{6}\right)_{2} \mathrm{CO}_{2}$ is $133^{\circ}$ indicating that the bending of $\mathrm{CO}_{2}$ interacting with this superalkali is $3 \%$ more than that in $\mathrm{CO}_{2}{ }^{-}$. NBO analysis in Fig. 3b shows that $0.90 e$ charge is transferred from $\mathrm{Mn}\left(\mathrm{B}_{3} \mathrm{~N}_{3} \mathrm{H}_{6}\right)_{2}$ to $\mathrm{CO}_{2}$ (see Table 1). More details of this calculation are given in ESI texts 6 and $7 . \dagger$

Wade-Mingos rule. The geometry of $\mathrm{B}_{9} \mathrm{C}_{3} \mathrm{H}_{12} \mathrm{CO}_{2}$ following the interaction of $\mathrm{CO}_{2}$ with $\mathrm{B}_{9} \mathrm{C}_{3} \mathrm{H}_{12}$ is shown in Fig. $3 \mathrm{c}$. In the $\mathrm{B}_{9} \mathrm{C}_{3} \mathrm{H}_{12}$ neutral cluster, the HOMO has a large electron density distribution around carbon atoms in the triangle plane (Fig. S4c $\dagger$ ) where $\mathrm{CO}_{2}$ prefers to bind. In this configuration the distance between $\mathrm{CO}_{2}$ and $\mathrm{B}_{9} \mathrm{C}_{3} \mathrm{H}_{12}$ is $2.32 \AA$ with the $\mathrm{O}-\mathrm{C}$ bonds are extended to 1.29 and $1.28 \AA$. These are about $3.3 \%-$ $4.4 \%$ longer than that in $\mathrm{CO}_{2}{ }^{-}$. In addition, the $\mathrm{O}-\mathrm{C}-\mathrm{O}$ angle is $131^{\circ}$ resulting in a structure that is $4 \%$ more bent than $\mathrm{CO}_{2}{ }^{-}$. Thus, both the stretching of the $\mathrm{O}-\mathrm{C}$ bonds and the bending of the $\mathrm{O}-\mathrm{C}-\mathrm{O}$ angle weaken the $\mathrm{O}-\mathrm{C}$ bonds of $\mathrm{CO}_{2}$, making it easy to activate.

NBO analysis in Fig. 3c and Table 1 shows that, after $\mathrm{CO}_{2}$ adsorption, the total charge transferred from $\mathrm{B}_{9} \mathrm{C}_{3} \mathrm{H}_{12}$ to $\mathrm{CO}_{2}$ is about $0.912 e$, which is more than that in noble metal atoms $(0.77 e) .{ }^{30}$ In addition, the $\mathrm{CO}_{2} \alpha$-spin electron configuration gains $0.89 e$ (details are given in ESI texts 8 and $9 \dagger$ ) making carbon more $\mathrm{sp}^{2}$ hybridized and causing $\mathrm{CO}_{2}$ to bend (see Fig. 3c).

Hückel's rule. The geometry of $\mathrm{C}_{5} \mathrm{NH}_{6}$ interacting with $\mathrm{CO}_{2}$ is shown in Fig. 3d. In the stable configuration, the distance between $\mathrm{CO}_{2}$ and $\mathrm{C}_{5} \mathrm{NH}_{6}$ is $1.04 \AA$. The $\mathrm{O}-\mathrm{C}$ bonds are extended to $1.35 \AA$ which is about 9.3\% longer than that in $\mathrm{CO}_{2}{ }^{-}$. In addition, the $\mathrm{O}-\mathrm{C}-\mathrm{O}$ bond angle is $129^{\circ}$ compared to $137^{\circ}$ in $\mathrm{CO}_{2}{ }^{-}$. Both these factors help to activate the $\mathrm{CO}_{2}$ molecule. NBO analysis in Fig. 3d shows that $0.632 e$ (details are given in ESI texts 10 and $11 \dagger$ ) charge is transferred from $\mathrm{C}_{5} \mathrm{NH}_{6}$ to $\mathrm{CO}_{2}$ (see Table 1). This amount of charge transfer is smaller than that in a noble metal gas $(0.77 e) .{ }^{30}$

\section{Comparison between the roles played by different superalkalis}

As discussed above, all superalkalis donate charge to $\mathrm{CO}_{2}$, although to a varying degree. This charge transfer results in bending of the $\mathrm{CO}_{2}$ molecule and weakening of the $\mathrm{C}-\mathrm{O}$ bond, thus making it easier to break. Here, we compare the relationship between the ionization potential of the superalkalis, the amount of charge they transfer to $\mathrm{CO}_{2}$, and the angle to which the $\mathrm{CO}_{2}$ bends as a result. This will allow us to identify the dominant factor for $\mathrm{CO}_{2}$ activation in Table 1. Comparing $\mathrm{Al}_{3}$ and $\mathrm{Mn}\left(\mathrm{B}_{3} \mathrm{~N}_{3} \mathrm{H}_{6}\right)_{2}$, whose IPs are comparable, the smaller volume of the superalkali leads to more $\mathrm{CO}_{2}$ bending. Besides, comparing $\mathrm{Al}_{3}$ and $\mathrm{C}_{5} \mathrm{NH}_{6}$, whose volumes are comparable, the lower the IP of superalkali, the more is the bending of $\mathrm{CO}_{2}$. In addition, note that among all the superalkalis studied, the IP of $\mathrm{Al}_{3}{ }^{+}$is not the lowest, the charge transferred is not the most, and the volume is not the smallest, yet it is able to bend the $\mathrm{CO}_{2}$ molecule the most. This comparison suggests that the quantitative nature of $\mathrm{CO}_{2}$ activation would depend upon the underlying electronic structure and size of the superalkali, although one can generally argue that the charge transfer made possible by low ionization potential is a driving factor in $\mathrm{CO}_{2}$ activation.

\section{Conclusions}

In summary, we show that a large family of superalkalis can be designed by going beyond the current use of the octet electron counting rule. These include the jellium shell closure rule valid for clusters of nearly free electron metals, the 18-electron rule valid for clusters containing transition metal atoms, the Wade-Mingos rule valid for compounds containing electron deficient boron, and Hückel's rule valid for organic molecules. While we have only used $\mathrm{Al}_{3}{ }^{+}, \mathrm{Mn}\left(\mathrm{B}_{3} \mathrm{~N}_{3} \mathrm{H}_{6}\right)_{2}{ }^{+}, \mathrm{B}_{9} \mathrm{C}_{3} \mathrm{H}_{12}{ }^{+}$, and $\mathrm{C}_{5} \mathrm{NH}_{6}{ }^{+}$as examples to illustrate our rational design principle, numerous superalkalis can now be designed using these electron counting rules, thus vastly expanding the scope of superatoms that mimic the chemistry of alkali atoms. To demonstrate the use of these superalkalis in chemical applications, we focused on $\mathrm{CO}_{2}$ activation which is the first step for producing fuels from $\mathrm{CO}_{2}$. Realizing that the addition of an extra electron results in a bent $\mathrm{CO}_{2}{ }^{-}$anion and that a superalkali with an ionization potential less than that of an alkali atom can easily transfer an electron, we studied the reaction of these superalkalis with $\mathrm{CO}_{2}$ by computing their equilibrium geometry and charge distribution. In all cases $\mathrm{CO}_{2}$ was found to be negatively charged, although the amount of charge transfer depends on the nature of the superalkali. In all cases, however, the $\mathrm{O}-\mathrm{C}-\mathrm{O}$ bond angle is found to be smaller than that in the gas phase $\mathrm{CO}_{2}^{-}$. These results based on density functional theory suggest that superalkalis can be used as catalysts for $\mathrm{CO}_{2}$ activation. 


\section{Theoretical methods}

The atomic structure optimizations, NICS values, and vibrational frequencies (IR and Raman) are calculated at the MP2 level of theory. ${ }^{31-33}$ Single point calculations of energy, molecular orbitals, band gaps, and NBO analysis are calculated at the CCSD level of theory, ${ }^{34,35}$ using optimized geometries obtained at the MP2 level. We used the $6-311+G^{*}$ basis set for all atoms ${ }^{36}$ embedded in the Gaussian 09 code. $^{37}$ Frequency analysis was performed at the same level of theory to ensure that there are no imaginary frequencies and the structures belong to minima in the potential energy surface. Thermodynamic stability, magnetic properties, and ELF analysis $^{38}$ are repeated using density functional theory (DFT) as implemented in the VASP. ${ }^{39}$ The projector augmented wave (PAW) method $^{40}$ and Perdew-Burke-Ernzerhof $(\mathrm{PBE})^{41}$ exchange correlation functional within the generalized gradient approximation (GGA) are used. Plane waves with a kinetic energy cutoff of $500 \mathrm{eV}$ are used to expand the valence electron wave functions. For all structural relaxations the convergence criteria for total energy and Hellmann-Feynman force are set to be $10^{-4} \mathrm{eV}$ and $10^{-2} \mathrm{eV} \AA^{-1}$, respectively. A unit cell with a vacuum space of $30 \AA$ in three directions is used in order to avoid virtual interactions. The first Brillouin zone is sampled by the $\Gamma$-point. ${ }^{42} A b$ initio molecular dynamics (AIMD) simulations are also performed to assess the thermal stability of different cations. A canonical (NVT) ensemble is adopted using the Nosé heat bath method. ${ }^{43}$

\section{Acknowledgements}

This work is partially supported by grants from the National Natural Science Foundation of China (NSFC-51471004), the National Key Research and Development Program of China (Grant No. 2016YFE0127300), and the Doctoral Program of Higher Education of China (20130001110033). P. J. acknowledges support by the U.S. Department of Energy, Office of Basic Energy Sciences, Division of Materials Sciences and Engineering under Award No. DE-FG02-96ER45579. T. Z. acknowledges the China Scholarship Council (CSC) for sponsoring his visit to Virginia Commonwealth University (VCU). Resources of the National Energy Research Scientific Computing Center are supported by the Office of Science of the U.S. Department of Energy under Contract No. DE-AC02$05 \mathrm{CH} 11231$.

\section{References}

1 S. N. Khanna and P. Jena, Phys. Rev. Lett., 1992, 69, 16641667.

2 S. N. Khanna and P. Jena, Phys. Rev. B: Condens. Matter, 1995, 51, 13705-13716.

3 G. L. Gutsev and A. I. Boldyrev, Chem. Phys. Lett., 1982, 92, 262-266.
4 G. L. Gutsev and A. I. Boldyrev, Chem. Phys., 1981, 56, 277283.

5 H.-J. Zhai, J. Li and L.-S. Wang, J. Chem. Phys., 2004, 121, 8369-8374.

6 B. Pathak, D. Samanta, R. Ahuja and P. Jena, ChemPhysChem, 2011, 12, 2423-2428.

7 B. Z. Child, S. Giri, S. Gronert and P. Jena, Chem. - Eur. J., 2014, 20, 4736-4745.

8 G. L. Gutsev, B. K. Rao, P. Jena, X.-B. Wang and L.-S. Wang, Chem. Phys. Lett., 1999, 312, 598-605.

9 S. Giri, S. Behera and P. Jena, Angew. Chem., Int. Ed., 2014, 53, 13916-13919.

10 H. Fang and P. Jena, J. Mater. Chem. A, 2016, 4, 4728-4737.

11 Q. Yao, H. Fang, K. Deng, E. Kan and P. Jena, Nanoscale, 2016, 8, 17836-17842.

12 P. Jena, J. Phys. Chem. Lett., 2015, 6, 1549-1552.

13 P. Jena, J. Phys. Chem. Lett., 2013, 4, 1432-1442.

14 J. Tong, Y. Li, D. Wu and Z.-J. Wu, Inorg. Chem., 2012, 51, 6081-6088.

15 N. Hou, Y. Li, D. Wu and Z.-R. Li, Chem. Phys. Lett., 2013, 575, 32-35.

16 S. Giri, S. Behera and P. Jena, J. Phys. Chem. A, 2014, 118, 638-645.

17 D. Wang, J. D. Graham, A. M. Buytendyk and K. H. Bowen, J. Chem. Phys., 2011, 135, 164308.

18 X. Li, H. Wu, X.-B. Wang and L.-S. Wang, Phys. Rev. Lett., 1998, 81, 1909-1912.

19 B. K. Rao and P. Jena, J. Chem. Phys., 1999, 111, 1890-1904.

20 X. Zhang, E. Lim, S. K. Kim and K. H. Bowen, J. Chem. Phys., 2015, 143, 174305.

21 P. Pyykkö and N. Runeberg, Angew. Chem., Int. Ed., 2002, 41, 2174-2176.

22 X. Li, B. Kiran, J. Li, H.-J. Zhai and L.-S. Wang, Angew. Chem., Int. Ed., 2002, 41, 4786-4789.

23 R. Pandey, B. K. Rao, P. Jena and M. A. Blanco, J. Am. Chem. Soc., 2001, 123, 3799-3808.

24 K. Wade, J. Chem. Soc. D, 1971, 792-793, DOI: 10.1039/ C29710000792.

$25 \mathrm{~K}$. Wade, in Advances in Inorganic Chemistry and Radiochemistry, ed. H. J. Emeléus and A. G. Sharpe, Academic Press, 1976, vol. 18, pp. 1-66.

26 D. M. P. Mingos, Acc. Chem. Res., 1984, 17, 311-319.

27 D. M. P. Mingos, Chem. Soc. Rev., 1986, 15, 31-61.

28 J. A. Wunderlich and W. N. Lipscomb, J. Am. Chem. Soc., 1960, 82, 4427-4428.

29 G. L. Gutsev, R. J. Bartlett and R. N. Compton, J. Chem. Phys., 1998, 108, 6756-6762.

30 X. Zhang, G. Liu, K.-H. Meiwes-Broer, G. Ganteför and K. Bowen, Angew. Chem., Int. Ed., 2016, 55, 9644-9647.

31 M. Head-Gordon, J. A. Pople and M. J. Frisch, Chem. Phys. Lett., 1988, 153, 503-506.

32 S. Sæbø and J. Almlöf, Chem. Phys. Lett., 1989, 154, 83-89.

33 M. J. Frisch, M. Head-Gordon and J. A. Pople, Chem. Phys. Lett., 1990, 166, 275-280.

34 G. D. Purvis and R. J. Bartlett, J. Chem. Phys., 1982, 76, 1910-1918. 
35 G. E. Scuseria, C. L. Janssen and H. F. Schaefer, J. Chem. Phys., 1988, 89, 7382-7387.

36 M. J. Frisch, J. A. Pople and J. S. Binkley, J. Chem. Phys., 1984, 80, 3265-3269.

37 M. Frisch, G. Trucks, H. B. Schlegel, G. Scuseria, M. Robb, J. Cheeseman, G. Scalmani, V. Barone, B. Mennucci and G. Petersson, Inc., Wallingford, CT, 2009, vol. 270, p. 271.

38 A. D. Becke and K. E. Edgecombe, J. Chem. Phys., 1990, 92, 5397-5403.
39 G. Kresse and J. Furthmüller, Phys. Rev. B: Condens. Matter, 1996, 54, 11169.

40 P. E. Blöchl, Phys. Rev. B: Condens. Matter, 1994, 50, 1795317979.

41 J. P. Perdew, K. Burke and M. Ernzerhof, Phys. Rev. Lett., 1996, 77, 3865.

42 H. J. Monkhorst and J. D. Pack, Phys. Rev. B: Solid State, 1976, 13, 5188-5192.

43 S. Nosé, J. Chem. Phys., 1984, 81, 511-519. 